
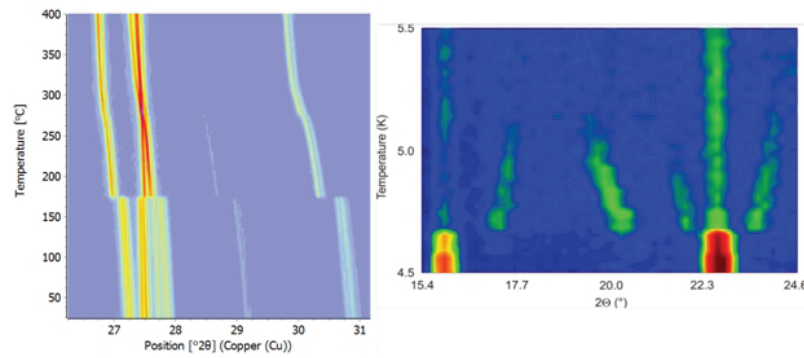

Figure 1. Temperature dependence above room temperature (left) and at low temperature (right) of $\mathrm{RbMnPO}_{4}$ demonstrating the existence of 5 different phases in the explored temperature range.

Keywords: multiferroic, phase transition,magnetoelectric

\section{MS14-P10 Enamel microstructure and tooth embryonic development}

Anna Kallistová ${ }^{1,2}$, Ivan Horáček ${ }^{3}$, Petr Čejchan ${ }^{2}$, Roman Skála ${ }^{1,2}$

1. Institute of Geochemistry, Mineralogy and Mineral Resources, Faculty of Science, Charles University, Albertov 2, Prague 2, Czech Republic.

2. Institute of Geology, Czech Academy of Sciences, v.v.i., Rozvojová 269, Prague 6, Czech Republic.

3. Department of Zoology, Faculty of Science, Charles University, Viničná 7, Prague 2, Czech Republic.

email: kallistova@gli.cas.cz

\section{INTRODUCTION}

Tooth enamel is one of the most resistant inorganic components in the mammalian bodies that significantly affect both quality and life expectancy of an individual; it depends on the mutual arrangement of aggregates of the hydroxyapatite crystallites (Koenigswald \& Clemens, 1992) and their characteristic properties. While the organization of aggregates is controlled by cooperation of cellular activity (ameloblasts) and pre-existing organic matrix (Boskey, 2007), the influence of Hap crystallites properties on the enamel quality has not been studied in detail up to now. In the present study we focus on the microstructure (i.e. crystallite size, micro-strain) of Hap of the laboratory minipig molars with different lengths of embryonic development stage and its implications for the final quality of the enamel.

\section{MATERIALS, METHODS}

Samples from 20 minipigs (aged 16 - 108 mths) were studied. First, second and third molar of each individual were used to obtain teeth with the same dental function but with different length of embryonic development.

\section{RESULTS}

While the crystallite size at $1 / 1$ direction increases from $M_{1}$ to $M_{3}$ for all samples studied, the micro-strain shows an opposite trend (Fig. 1). The prolonged period of $M_{3}$ molar formation leads to enamel with lowest degree of lattice imperfection and, hence, arguably yields tooth with highest resistance to both mechanical and chemical damage and can perform its function for a long time period to ensure an adequate nutrition. Moreover, by comparing the young and old individuals, we showed that the enamel microstructure of individual molar types is time invariant.

\section{CONCLUSIONS}

In the present study we showed that the effect of mechanical abrasion and/or the chemical degradation caused by the oral environment (hence the subject's age) on the microstructure can be excluded. We also demonstrated that the length of the tooth's embryonic development stage has a positive effect on the quality of its enamel.

\section{REFERENCES}

Boskey, A. L. (2007). Mineralization of bones and teeth. Elements, 3, 385-391. Koenigswald, W. von and Clemens, W. A. (1992). Levels of complexity in the microstructure of mammalian enamel and their application in studies of systematics. Scan. Micr., 6, $195-218$ 




Figure 1. Crystallite size along $a$ axis (red circles, left ordinate) and micro-strain (blue triangles, right ordinate) of various molar types. Crystallite size along the direction of $\mathrm{c}$ axis shows analogues behavior.

Keywords: crystallite size, micro-strain, enamel development
MS14-P11 High-temperature, high-pressure hydrothermal synthesis of uranium silicates and germanates

\author{
Kwang-Hwa Lii ${ }^{1}$ \\ 1. Department of Chemistry, National Central University, Zhongli, \\ Taiwan \\ email: liikh@cc.ncu.edu.tw
}

Most uranium minerals can be classified as oxidized species in which $U$ is fully oxidized to $\mathrm{U}^{6+}$, and reduced species, in which $U$ occurs primarily as $\mathrm{U}^{4+}$. Uranyl silicates are an important group of U(VI) minerals in the altered zones of many uranium deposits. ${ }^{1}$ One naturally occurring U(IV) silicate exists, namely coffinite $\left(\mathrm{USiO}_{4}\right)$, which is an important ore mineral for uranium. Numerous synthetic U(VI) silicates and germanates containing organic amines or alkali metals as countercations have also been reported. ${ }^{2}$ In contrast to the U(VI) compounds, the chemistry of materials containing $U(V)$ is considerably less developed owing to the tendency of $\mathrm{U}^{5+}$ to either oxidize to $\mathrm{U}^{6+}$ or disproportionate to $\mathrm{U}^{4+}$ and $\mathrm{U}^{6+}$. We have synthesized a U(V) silicate and a germanate by a high-T, high-P hydrothermal method in gold ampoules contained in a high-pressure reaction vessel at ca. $600{ }^{\circ} \mathrm{C}$ and $170 \mathrm{MPa} \cdot{ }^{3 a, 3 b}$ Following the synthesis of the U(V) compound, a number of mixed-valence uranium silicates and germanates have been synthesized, for example, a mixed-valence U(IV,V) silicate, $\mathrm{Cs}_{2} \mathrm{~K}(\mathrm{UO}) \mathrm{Si}_{4} \mathrm{O}_{12} 3 c \mathrm{U}(\mathrm{IV}, \mathrm{VI})$ germanate, $\mathrm{Cs}_{8} \mathrm{U}\left(\mathrm{UO}_{2}\right)_{3}\left(\mathrm{Ge}_{3} \mathrm{O}_{9}\right)_{3} \cdot 3 \mathrm{H}_{2} \mathrm{O}^{3}{ }^{3} \mathrm{~d} \quad \mathrm{U}(\mathrm{V}, \mathrm{VI})$ germanates, $\mathrm{A}_{3}\left(\mathrm{U}_{2} \mathrm{O}_{4}\right) \mathrm{Ge}_{2} \mathrm{O}^{3}\left(\mathrm{~A}^{3}=\mathrm{K} b, \mathrm{Cs}\right){ }^{3 e}$ and a U(IV,V,VI) silicate, ${ }^{\mathrm{Na}} \mathrm{U}^{\mathrm{IV}} \mathrm{O}_{2}\left(\mathrm{U}^{\overline{\mathrm{V}}} \mathrm{O}\right)_{2}\left(\mathrm{U}^{\mathrm{V} / \mathrm{VI}} \mathrm{O}_{2}\right)_{2} \mathrm{Si}_{4} \mathrm{O}_{16},{ }^{3}$ in which three oxidation states of uranium co-exist in one compound. In addition, tetravalent-uranium compounds, $\mathrm{Cs}_{2} \mathrm{USi}_{6} \mathrm{O}_{15}$ and $\mathrm{Cs}_{4} \mathrm{UGe}_{8} \mathrm{O}_{20}, 3 g, 3 h$ were also synthesized. All members in the family of uranium silicates and germanates with the oxidation states of uranium from +4 to +6 have been observed.

\section{References}

1. (a) Burns, P. C. Rev. Mineral. 1999, 38, 23-90. (b) Finch, R. J.; Murakami, T. Rev. Mineral. 1999, 38, 24-179.

2. (a) Wang, X.; Huang, J.; Jacobson, A. J. J. Am. Chem. Soc. 2002, 124, 15190-15191. (b) Lin, C.-H.; Chiang, R.-K.; Lii, K.-H. J. Am. Chem. Soc. 2009, 131, 2068-2069.

3. (a) Chen, C.-S.; Lee, S.-F.; Lii, K.-H. J. Am. Chem. Soc. 2005, 127, 12208-12209. (b) Nguyen, Q. B.; Chen, C.-L.; Chiang, Y.-W.; Lii, K.-H. Inorg. Chem. 2012, 51, 3879-3882. (c) Lee, C.-S.; Wang, S.-L.; Lii, K.-H. J. Am. Chem. Soc. 2009, 131, 15116-15117. (d) Nguyen, Q. B.; Liu, H.-K.; Chang, W.-J.; Lii, K.-H. Inorg. Chem. 2011, 50, 4241-4243. (e) Lin, C.-H.; Lii, K.-H. Angew. Chem. Int. Ed. 2008, 47, 8711-8713. (f) Lee, C.-S.; Lin, C.-H.; Wang, S.-L.; Lii, K.-H. Angew. Chem. Int. Ed. 2010, 49, 4254-4256. (g) Liu, H.-K.; Lii, K.-H. Inorg. Chem. 2011, 50, 5870-5872. (h) Nguyen, Q. B.; Lii, K.-H. Inorg. Chem. 2011, 50, 9936-9938.

Keywords: uranium, silicate, germanate, hydrothermal 